\title{
O catador de materiais recicláveis: um agente ambiental
}

\section{The collector of recyclable materials: an environmental agent}

Lucimare Ferraz ${ }^{1}$

Mara Helena de Andrea Gomes ${ }^{2}$

Maria Assunta Busato ${ }^{3}$

\section{Resumo}

A atividade de catador de material reciclável configura-se como um meio de inclusão social na medida em que gera recursos para compra de alguns bens de consumo. O objetivo neste ensaio é apresentar aspectos sobre o universo de trabalho dos catadores e, com isso, gerar reflexões sobre ambiente, recursos e trabalho. Na tarefa de coleta, separação, manuseio e transmutação do lixo em mercadoria, encontramos o modo de sobrevivência de um novo agente, que, ao se expor a diversos riscos de acidentes e de saúde, também se encontra socialmente vulnerável. Não possui qualquer tipo de apoio dos governos, está à mercê da própria sorte em caso de acidentes, adoecimento, oferta de material e rendimento. Faz-se necessário, portanto, que os profissionais atuantes nas unidades de saúde e do serviço social (re)conheçam as fragilidades do trabalho na catação do lixo e implementem ações de proteção.

Palavras-chave: Agente ambiental. Material reciclável. Trabalho.

\begin{abstract}
The activity of recyclable material collectors is configured as a means of social inclusion as it generates funds for the purchase of consumer goods. This essay aims to present aspects of the universe of the work of these collectors for the purpose of generating reflections on the environment, resources and labor. In the task of collecting, sorting, handling and transforming of garbage into a commodity, we found the survival mode of new agents, who expose themselves to the various risks of accidents and health and who are also socially vulnerable. Furthermore, there is no government support of any kind and they are at the mercy of fate in case of accidents, illness, material supply and income. Therefore, it is necessary for professionals working in health facilities and social services to recognize the precarious state of working with the collection of recyclable material and implement protective actions.
\end{abstract}

Keywords: Environmental agent. Recyclable material. Labor.

Texto submetido em 16 de junho de 2012 e aceito para publicação em 07 de agosto de 2012.

1 Doutora em Ciências pela Universidade Federal de São Paulo; Professora adjunta da Universidade Comunitária da Região de Chapecó (Unochapeco) e da universidade do estado de Santa Catarina (Udesc). Endereço: Av. Senador Atílio Fontana, 591-E, Bloco R, Efapi, CEP 89809-000, Chapecó - SC, Brasil. E-mail: Iferraz@unichapeco.edu.br

Doutora em Sociologia Universidade Política Católica PUC-SP. Professora adjunta da Universidade Federal de São Paulo. Endereço: Rua Borges Lagoa, 1341, Vila Clementino, CEP 04038-034, São Paulo - SP, Brasil. E-mail: maraandrea@unifesp.br

${ }^{3}$ Doutora em Biologia pela Universidade de Barcelona. Professora adjunta da Universidade Comunitária da Região de Chapecó (Unochapeco). Endereço: Av. Senador Atílio Fontana, 591-E, Bloco R, Efapi, CEP 89809-000, Chapecó - SC, Brasil. E-mail: assunta@unochapeco.edu.br 


\title{
Introdução
}

Os materiais recicláveis vêm sendo discutidos no âmbito dos modelos atuais do desenvolvimento sustentável. Porém, desde a Revolução Industrial, o solo e o subsolo passaram a se constituir em grandes receptáculos de praticamente todos os resíduos sólidos gerados pela sociedade consumidora de produtos industrializados e descartáveis, configurando-se em problema relacionado às questões ambientais (MEDEIROS e MACEDO, 2006). Assim, à escassez dos recursos naturais, seguiram-se a degradação ambiental e o esgotamento de espaço físico para o armazenamento dos resíduos produzidos pela geração e acúmulo de lixo.

\begin{abstract}
Dentre as alternativas de tratamento para o lixo urbano, a reciclagem configura-se como importante elemento, pois possibilita o reaproveitamento de materiais descartados novamente ao circuito produtivo e traz benefícios ambientais através da economia de recursos naturais, energia e água. Além do inquestionável aspecto ambiental, a reciclagem possibilita ganhos sociais ao absorver no seu circuito produtivo os catadores de materiais recicláveis. Esses trabalhadores desempenham um papel preponderante para o processo de reciclagem, pois, atualmente, o fruto de seu trabalho é ponto de partida para o abastecimento, com matérias-primas, das indústrias de reciclagem. (MEDEIROS e MACEDO, 2006, p. 69).
\end{abstract}

Segundo Bosi (2008, p. 67), no Brasil o processo de reciclagem em grande escala somente se tornou viável quando o recolhimento e a separação dos resíduos se evidenciaram como uma tarefa de baixo custo. De acordo com este autor, tal atividade necessita ser realizada "[...] por trabalhadores cuja remuneração compensasse investimentos de tecnologia para o surgimento do setor de produção de material reciclado". Essa força de trabalho é composta, então, por trabalhadores sem contrato e com uma produtividade que possa ser definida pelo pagamento por produção. Dito de outra forma: se não fosse a mão de obra barata do catador, o processo de reciclagem não seria lucrativo a ponto de estimular empresários a investirem nesse nicho de mercado.

Há muito tempo a reciclagem no Brasil vem sendo sustentada pelo trabalho informal dos catadores (SILVIA e JOIA, 2008). Cerca de $90 \%$ dos materiais recicláveis que chegam às indústrias de reciclagem advêm do trabalho dos catadores, que possuem habilidades para identificar, coletar e separar o material desprezado pela sociedade (ABREU, 2001 apud SILVIA e JOIA, 2008).

O trabalho da catação se tornou mais significativo a partir da década de 1990, quando cresceu o montante de material coletado à custa de maior número de pessoas envolvidas (SEVERO, 2008). Esse fato deve-se ao processo de reciclagem, à reinserção do lixo na sociedade do capital (LEAL et al., 2002) e ao aumento das taxas de desemprego a partir da década de 1980.

Entretanto, a valorização deste trabalho é relativamente nova, pois até a década de 80 a ocupação de catador era extremamente desvalorizada, incorporava aqueles que viviam nas ruas ou nos lixões como indigentes e que conviviam com urubus e tratores na busca por alimentos, roupas e materiais para vender. Além disso, ajudaram a compor lendas urbanas no imaginário infantil - lembremos: "Velho das Garrafas" e o "Homem do Saco" (DAGNINO, 2004, p. 59).

Diante da emergência do debate deste tema, este ensaio tem por objetivo apresentar aspectos sobre o universo de trabalho dos catadores de materiais recicláveis, na perspectiva de gerar reflexões sobre ambiente, recursos e trabalho. 


\section{A Inclusão Social por meio do Lixo}

Além do desenvolvimento e manutenção das indústrias de matérias recicláveis, o crescimento de trabalhadores na catação também está relacionado com o aumento do desemprego e da precarização do trabalho a partir da década de 1990. Segundo Pochmann (2003), a partir dessa década, o Brasil passa a registrar modificações no seu mercado de trabalho. Com a inclusão de políticas neoliberais de desregulamentação, flexibilização e menor proteção social do trabalho, cresceram as formas precárias de ocupações, havendo o aprofundamento da exclusão no campo do trabalho. Segundo Reis (2006), durante a década de 90 o aumento da taxa de desemprego no Brasil foi intensa; a liberalização comercial, a incorporação de novas tecnologias na produção e no aumento do comércio internacional resultaram numa diminuição das vagas de trabalho.

Neste quadro de transições, de acordo com Gorbán (2004), a rua constituiu-se, para os desempregados, como um local dentro do mercado de trabalho. Entre esses trabalhadores, encontramos os catadores de material reciclável, que adentram no cenário urbano catando papel, vidro, lata e outros materiais. Na maioria dos casos, estes trabalhadores são os agentes iniciais do circuito de produção da reciclagem e sustentabilidade ambiental. E o que se vê nos perímetros urbanos das nossas cidades é um número significativo de homens, mulheres, crianças e adolescentes sendo absorvidos de forma muito rápida pelo mercado de trabalho informal e desqualificado da catação de lixo ou de material reciclável.

Segundo Bosi (2008), os catadores constituíram trajetórias ocupacionais marcadas pela precariedade das ocupações, pois, parte deles nasceu e cresceu no campo, seu aprendizado para o trabalho consistiu nos afazeres da agricultura, suinocultura e pecuária; e, ao migrarem paras as cidades, acabam desempenhando ocupações que não exigem qualificação profissional.

Ao referirem-se ao processo histórico de exclusão dos catadores de lixo, Cavalcante e Franco (2007) ressaltam que a exploração da força de trabalho dos catadores possui raízes históricas nas consequências do êxodo rural. Esse mesmo panorama foi encontrado em outros estudos realizados no Brasil (MEDEIROS e MACEDO, 2006; BOSI, 2008; SEVERO, 2008). "Em grande parte, são pessoas que têm sua origem no meio rural e que vieram buscar na cidade melhores condições de vida. Chegando à cidade, se defrontam com a nova conformação produtiva, maiores restrições de acesso ao mercado de trabalho formalizado, tendo de ocupar, portanto, a franja produtiva, em atividades como a catação" (SEVERO, 2008, p. 24).

No artigo "Catador de material reciclável: uma profissão para além da sobrevivência?", Medeiros e Macedo (2006, p. 69) consideram que os catadores são excluídos do mercado formal de trabalho e "[...] encontram na catação a possibilidade de garantir sua sobrevivência, mesmo executando um trabalho desprovido de qualquer garantia trabalhista e, a partir daí, sentem-se novamente incluídos"; porém, destacam: “[...] trata-se de uma inclusão perversa, pois como se pode verificar, com a lucratividade assegurada pelos processos de reciclagem, estes estão sendo realizados por pessoas de diferentes segmentos e até mesmo por organizações terceirizadas, o que conduz paulatinamente para nova exclusão dos catadores" (p. 70).

Portanto, “[...] falar em exclusão é rotular como uma quantificação negativa que designa falta, sem dizer de quê e ocultar-se a necessidade de se analisar positivamente no que consiste a ausência" (CASTEL, 2008, p. 19). Os termos "incluídos" e "excluídos" "são da mesma substância" para Sawaia (1999, p. 108), "[...] e formam um par indissociável, que se constitui na própria relação", já que as relações de uma sociedade incluem e excluem ao mesmo tempo os indivíduos dela pertencentes.

Logo, interpretar o sentido do trabalho para o catador de material reciclado é fundamental para compreender o comportamento desse trabalhador num mundo pós-moderno, "no qual a dimensão profissional ainda tem papel fundamental para a formação da identidade e para o bem estar das pessoas" (CAVAZOTTE, LEMOS e VIANA, 2012, p. 165). 


\section{Perfil do Agente Ambiental do Catador de Lixo}

Para esse universo de trabalhadores, Severo (2008, p. 23) descreve dois tipos de sujeitos que desempenham as atividades de catadores, a saber: "[...] os mais velhos, desempregados pela modificação das novas características industriais e redução da demanda nos demais setores periféricos, e os mais jovens, que antes eram absorvidos por estes mercados de trabalho, mas hoje em dia tendem a aumentar o número de desempregados estruturais, ocupando atividades informais, em especial a catação".

Estudos realizados com populações de catadores apresentam um perfil semelhante (MAGERA, 2003; JUNCÁ, 2004; MEDEIROS e MACEDO, 2006; BOSI, 2008; SEVERO, 2008). Com relação à idade, o estudo de Medeiros e Macedo (2006) revelou uma predominância de sujeitos entre 30 e 60 anos; Ferreira (2007) encontrou 68\% de catadores com idade superior a 30 anos; pelos dados de Puech (2008), a faixa etária mais prevalente foi de 30 a 40 anos de idade; Severo (2008) constatou que a maioria dos trabalhadores encontra-se na faixa dos 40 aos 60 anos. Cerca de $70 \%$ dos pesquisados por Bosi (2008) estavam entre $31 \mathrm{e}$ 60 anos e, na faixa de idade mais avançada (entre 41 e 60 anos), quase 50\%. Silva e Jóia (2008) verificaram que $2 \%$ de catadores tinham idade entre 14 e 21 anos, e $85 \%$ entre 21 e 60 anos; destes, $40 \%$ estavam entre 50 e 60 anos de idade - nessa pesquisa, $13 \%$ dos catadores estavam incluídos na faixa etária dos idosos (acima de 60 anos de idade).

Para Ferreira (2007), partem para a atividade de catador pessoas em idade economicamente ativa, mas com baixa escolaridade, sem chances de concorrer a uma vaga no mercado formal de trabalho. Outrossim, Severo (2008, p. 87) observa que os motivos alegados pelos mais velhos para seu desemprego geralmente estão relacionados a problemas de saúde, em razão de sua idade avançada, e destaca que "[...] os catadores mais jovens, em sua maioria, não experimentaram atividades formais, iniciando o trabalho já enquanto catadores ou em outras atividades informais [...] e parecem encarar a atividade como qualquer outra, algo comum". Segundo os entrevistados de Medeiros e Macedo (2006), a catação torna-se uma atividade de sobrevivência para parcelas de excluídos, uma vez que em tal atividade a idade não constitui fator excludente, ao contrário do que se exige no reingresso ao mercado formal de trabalho.

Outra questão importante levantada por Bosi (2008) é a de que o conhecimento mais útil para uma atividade que não requer escolaridade refere-se às operações matemáticas básicas na conferência da pesagem e do pagamento do material recolhido. Velloso (2005), por sua vez, reflete sobre a fragilidade do poder de negociação dos catadores de lixo, uma vez que os constituintes dessa categoria de trabalhadores possuem pouca ou nenhuma escolaridade e baixa autoestima.

Os participantes do estudo realizado por Medeiros e Macedo (2006) eram predominantemente semianalfabetos ou tinham ensino fundamental completo; na pesquisa de Ferreira (2007), 25\% eram analfabetos, $37 \%$ cursaram até o ensino básico, $32 \%$ o fundamental e $6 \%$ até o ensino médio. A maioria dos entrevistados por Severo (2008) tinha o ensino básico incompleto e não realizou cursos de profissionalização. Já Silva e Joia (2008, p. 31) observaram que 42\% dos catadores de recicláveis eram pessoas que não possuíam escolaridade (ou eram analfabetos ou somente alfabetizados funcionais), e 54\% possuíam apenas o ensino fundamental. Para essas autoras, “[...] a baixa escolaridade desses trabalhadores aliada à falta de qualificação profissional contribuiu significativamente para a exclusão desses trabalhadores no mercado formal de trabalho".

Além dessa constatação, a baixa escolaridade também está associada à autoimagem que os catadores fazem de sua profissão e posição social. Muitos deles associam a falta de estudos à condição de ter de viver do trabalho de catação, um fator que direciona para a exclusão do mercado formal de trabalho (MEDEIROS e MACEDO, 2006).

Gonçalves (2004) registra que, mesmo sendo uma característica comum desse segmento de trabalhadores, a baixa escolaridade ou qualificação profissional não deve ser considerada como o agente causador direto da realização da catação como forma de sobrevivência. Tal explicação seria uma fuga teórica que hiperdimensiona os indivíduos que se encontram em tal situação, desconsiderando, portanto, elementos 
estruturais do sistema produtivo apontado como responsável pelo seu desemprego e, em especial, por sua pobreza (SEVERO, 2008).

\section{Considerações Finais}

É certo que o lixo é composto por materiais recicláveis, mas não é menos certa a designação de lixo, uma vez que foi desprezado exatamente por não possuir mais utilidade para alguém. Perdeu valor de uso para quem o descarta e, na maioria das vezes, não tem valor de troca. Estes atributos são recuperados, no entanto, quando o lixo retorna ao circuito da produção, conformando um ciclo que tem início com a recuperação - por outros agentes do mercado - de suas propriedades químicas e/ou físicas ao assumir as formas de "lixo orgânico" e "material reciclável". Esta metamorfose do lixo em material utilizável por meio de outros processos de transformação acarreta a necessidade de agentes que efetuem a separação, naquilo que foi desprezado, entre as propriedades aproveitáveis e as que não terão mais proveito algum para o mercado.

O trabalho de agente ambiental envolve, portanto, dispêndio de energia, de tempo e de instrumentos apropriados para as tarefas desempenhadas no processo: recolher, separar e transportar o material coletado para seu novo endereço, onde será novamente transformado e distribuído. É exatamente nesta tarefa de coleta, separação, manuseio e transmutação do lixo em mercadoria que encontramos o modo de sobrevivência dos "nossos" agentes, que, ao se exporem a diversos riscos de acidentes e de saúde, também estão socialmente vulneráveis.

Diante disso, entendemos que, na perspectiva de promover o bem-estar ocupacional desses sujeitos, faz-se necessário que os profissionais atuantes nas unidades de saúde e do serviço social (re)conheçam as fragilidades do trabalho na catação do lixo e, dentro das suas capacidades laborais, implementem ações de proteção. Sobre esse aspecto, Lara (2011, p. 84) ressalta que é importante construir "[...] espaços criativos e aglutinadores das demandas da saúde", bem como "[...] articular o momento da (re)reprodução social (consumo mais produção), com o momento da produção (locais de trabalho)", acrescentando que "[...] as reivindicações em defesa da saúde do trabalhador devem ser encaradas como principal agenda das lutas dos trabalhadores, dos profissionais e dos gestores das políticas sociais". Ainda, segundo Pereira e Teixeira (2011), é imprescindível a construção de políticas públicas que possibilitem o exercício efetivo de direitos por parte de milhares de catadores do país, que estão em situação de pobreza e vulnerabilidade social.

Partindo da premissa de que as novas configurações capitalistas estão, cada vez mais, excluindo as pessoas com idade economicamente ativa do mercado formal de trabalho, a atividade de catação configura-se como um meio de inclusão social na medida em que gera recursos para compra de alguns bens de consumo. Porém, isso não os desloca da condição de excluídos do mercado formal para o acesso à seguridade social plena.

As famílias catadoras, na maioria dos casos, não possuem qualquer tipo de apoio dos governos locais, estando à mercê da própria sorte em caso de chuva, de estrago do carrinho, acidentes, adoecimento, oscilações de oferta de material e de rendimento. Pelo fato de não possuírem maquinários e equipamentos como prensa, balança e automóvel, os catadores acabam negociando o seu material com atravessadores indivíduos ou organizações - que pesam, recolhem, conduzem e negociam com as empresas de reciclagem. Em alguns casos, estão/são reféns desses atravessadores, porque estes lhes adiantam/emprestam dinheiro, configurando uma dívida a ser paga com material reciclável.

Deste modo, entendemos que o catador faz parte de um circuito produtivo pelo lado perverso, já que não possui poder de negociação, e a barganha, muitas vezes, é explorada pelo detentor do capital. Apesar da exploração característica desta atividade, esse é o recurso encontrado e até mesmo a opção das famílias.

Os catadores, ao caminharem pelas ruas, nos lembram do lixo que produzimos, da natureza e do ambiente sociocultural em que vivemos. Não há como não pensar no lixo que produzimos quando nos deparamos com um catador. Eles são os agentes ambientais, são figuras (vivas) da representação da preservação da natureza. Como relatou um catador: "Imagine se nós não existíssemos?!". 


\section{Referências}

BOSI, A. P. A organização capitalista do trabalho "informal": o caso dos catadores de recicláveis. Revista Brasileira de Ciências Sociais, v. 23, n. 67, jun. 2008.

CASTEL, R. As metamorfoses da questão social: uma crônica do salário. 8. ed. Petrópolis: Vozes, 2008.

CAVALCANTE, S.; FRANCO, M.F. A. Profissão perigo: percepção de risco à saúde entre os catadores do Lixão do Jangurussu. Revista Mal-Estar e Subjetividade, v. 7, n. 1, p. 211-232, mar. 2007.

CAVAZOTTE, F. S. C. N.; LEMOS, A. H. C.; VIANA, M. D. A. Novas gerações no mercado de trabalho: expectativas renovadas ou antigos ideais? Cad. EBAPE.BR, v. 10, n. 1, 162-180 p. mar. 2012.

DAGNINO, R. S. 2004. Um olhar geográfico sobre a questão dos materiais recicláveis em Porto Alegre: sistemas de fluxos e a (in)formalidade, da coleta à comercialização. 2004. Monografia (Graduação em Geografia) - Universidade Federal do Rio Grande do Sul, Porto Alegre, 2004.

FERREIRA, S. L. Os catadores de lixo na construção de uma nova cultura: a de separar o lixo e da consciência ambiental. Disponível em: <www.sociologia.ufsc.br/npms/maira_g_daniel.pdf>. Acesso em: set. 2007.

GONÇALVES, R. S. Catadores de materiais recicláveis: estudo de suas trajetórias de vida, trabalho e saúde. 2004. Dissertação (Mestrado em Saúde Pública) - Fundação Oswaldo Cruz, Rio de Janeiro, 2004.

GORBÁN, D. Reflexiones alrededor de los procesos de cambio social en Argentina: el caso de los cartoneros. Revista Electrónica de Estudios Latinoamericanos, v. 2, n. 8, p. 3-15, Buenos Aires, jul./set. 2004.

JUNCÁ, D.C. M. Mais que sobras e sobrantes: vida e trabalho no lixo. 2004. Tese (Doutorado em Saúde Pública) Fundação Oswaldo Cruz, Rio de Janeiro, 2004.

LARA, R. Saúde do trabalhador: considerações a partir da crítica da economia política. Revista Katálysis, v. 14, n. 1, p. 78-85 jun. 2011.

LEAL, A. C. et al. A reinserção do lixo na sociedade do capital: uma contribuição ao entendimento do trabalho na catação e na reciclagem. Terra Livre, São Paulo/SP, v. 2, p. 177-190, 2002.

MAGERA, M. Os empresários do lixo: um paradoxo da modernidade. Campinas, SP: Átomo, 2003.

MEDEIROS, L. F. R; MACEDO, K. B. Catador de material reciclável: uma profissão para além da sobrevivência? Psicologia e Sociedade, v. 18, n. 2, p. 62-71 ago. 2006.

PEREIRA, M. C. G.; TEIXEIRA, M. A. C. A inclusão de catadores em programas de coleta seletiva: da agenda local à nacional. Cad. EBAPE.BR, v. 9, n. 3, p. 895-913 set. 2011.

POCHMANN, M. As possibilidades do trabalho e a nova economia no Brasil. In: RUBEN, G.; WAINER, J.; DWYER, T. (Org.). Informática, organizações e sociedade no Brasil. São Paulo: Cortez, 2003.

PUECH, M. P. S. R. Grupos de catadores autônomos na coleta seletiva no município de São Paulo. 2008. Dissertação (Mestrado em saúde Pública) - Faculdade de Saúde Pública, Universidade de São Paulo, São Paulo, 2008.

REIS, M. C. Os impactos das mudanças na demanda por trabalho qualificado sobre o desemprego por nível de qualificação durante os anos noventa no Brasil. Revista Brasileira de Economia, v. 60, n. 3, p. 297-319 set. 2006.

SAWAIA, B. B. As Artimanhas da Exclusão: uma análise ético-psicossociológica. Rio de Janeiro: Vozes, 1999.

SEVERO, R. G. Catadores de materiais recicláveis da cidade de Pelotas: situações de trabalho. 2008. Dissertação (Mestrado em Ciências Sociais) - Universidade Federal de Pelotas, Pelotas, 2008. 
SILVA, M. do S. F; JOIA, P. R. Situação sócio-econômica dos catadores de materiais recicláveis na cidade de Aquidauana/MS. Revista Terra Plural, v. 2, p. 25-39, 2008.

VELLOSO, M. P. Os catadores de lixo e o processo de emancipação social. Ciência e Saúde coletiva, v. 10 (sup), p. 49-61, 2005. 